\title{
The Association Between Social Resources and Depressive Symptoms Among Chinese Migrants and Non-Migrants Living in Guangzhou, China
}

\author{
Chan Kit Hoi, ${ }^{1}$ Wen Chen, ${ }^{2,3}$ Fangjing Zhou, ${ }^{2,3}$ Kalon Sou, ${ }^{1}$ and Brian J. Hall ${ }^{1,4}$ \\ 1 Global and Community Mental Health Research Group, Department of Psychology, University of Macau, Taipa, Macau (SAR), \\ People's Republic of China \\ ${ }^{2}$ Faculty of Medical Statistics and Epidemiology, School of Public Health, Sun Yat-sen University, Guangzhou, People's Republic of \\ China \\ 3 Sun Yat-sen Center for Migrant Health Policy, Guangzhou, People's Republic of China \\ ${ }^{4}$ Department of Health Behavior and Society and Department of Epidemiology, Johns Hopkins Bloomberg School of Public \\ Health, Baltimore, Maryland, USA
}

\begin{abstract}
$B$ ackground: Depression is a commonly studied mental disorder affecting Chinese internal (i.e., rural-to-urban) migrants. Social resources effectively reduce depression for many communities experiencing adversities. This study evaluated social-level risk factors for depression between internal migrant and non-migrant Chinese living in mainland China. Method: We conducted a random populationlevel survey among migrants and local residents living in Guangzhou, China. Data were collected using face-to-face interviews. We used items from the Social Support Rating Scale to measure social resource dimensions, including social network size, emotional support, structural social capital, and one (self-developed) item that measured belonging (an element of social cohesion). The Patient Health Questionnaire-9 measured depression. Correlation and regression analyses of the partial sample $(n=$ 678 ) were conducted to estimate the association between social resources and depression for migrants ( $n=383$ ) and non-migrants $(n=295)$. Results: Stratified regression analysis demonstrated that for migrants, greater belonging was associated with less depression, while age and larger friendship social network size was related to less depression among non-migrants. Conclusion: Differences emerged in our sample with regard to the types of social resources that are protective against depression between migrants and non-migrants. Interventions that provide opportunities for migrants to better integrate and feel welcomed into their new communities may reduce their depression symptoms.
\end{abstract}

Keywords: migration, China, depression, mental health, social resources

In mainland China, there is a massive internal Chinese migrant population (i.e., Chinese rural-to-urban migrants). Megacities such as Guangzhou have undergone rapid economic development and changes in population composition, and an increasing number of migrants may experience a mental health burden. For the general population, studies showed the 12-month prevalence for depression was $1.1 \%$ to $3.3 \%$ (Chen, Cheng, Huang, Liu, \& Luo, 2012; Lee et al., 2007; Lu et al., 2008; Ma et al., 2009; Zhang et al., 2008), while the lifetime prevalence was between $0.5 \%$ and $6.1 \%$ in China (Lee et al., 2007; Lee et al.,
2009; Li et al., 2008; Lu et al., 2008; Ma et al., 2009; Wei et al., 2010; Zhang et al., 2008; Zhao et al., 2009). Furthermore, in a meta-analytic review, it was shown that the prevalence of depressive symptoms in China was $2.3 \%$ for 12-months and 3.3\% for lifetime respectively ( $\mathrm{Gu}$ et al., 2013). In comparison, Chinese migrants were more vulnerable to depression, with a prevalence between $12.8 \%$ to 21.4\% (Mou et al., 2011; Qiu et al., 2011; Wong, He, Leung, Lau, \& Chang, 2008).

Migrant communities are exposed to social and environmental factors that may lead to poor mental health 
(Ismayilova et al., 2014; Li et al., 2009; Lu, Hu, \& Treiman, 2012; Mou et al., 2011; Qiu et al., 2011). Among the multiple factors affecting mental health, migrant status appears to be associated to depression substantially and uniquely in China due to the household registration system, or 'hukou' system. The hukou is a system of household registration that binds residents to their rural or urban area of birth (Chan \& Buckingham, 2008). The system divides people into two kinds of citizenship: 'agricultural' and 'non-agricultural' (Wu \& Treiman, 2004). Although people from rural areas are able to move to urban areas for economic advantages, jobs, and increased chances for social mobility, they might be exposed to risk factors such as interpersonal violence and perceived discrimination that lead to poorer mental health (Teng, Hall, \& Li, 2014; Lin et al., 2011).

Several studies conducted in China and elsewhere suggest that when people migrate to other cities or countries they are at increased risk for poor mental health (Ismayilova et al., 2014; Li et al., 2009; Lu et al., 2012; Mou et al., 2011; Qiu et al., 2011). Aside from individual-level risk factors such as gender, marital status, age, education level, and employment status (Li, Stanton, Fang, \& Lin, 2006; Li et al., 2009), the lack of adequate social network supports are implicated in poor mental health following numerous life adversities, including migration (Záleská, Brabcová, \& Vacková, 2014). Social connectedness and reliance on social support is important to migrants as this may mitigate experiences of discrimination on mental health (Veling, Hoek, Wiersma, \& Mackenbach, 2009) and an enhanced the ability to obtain valuable resources from local people and peers to handle adverse situations (Caplan, 1974). Thus, social network supports are considered to be an important resource for information, emotional care, and direct instrumental assistance (Van den Akker-Scheek, Stevens, Spriensma, \& van Horn, 2004; Whittmore, Rankin, Callahan, Leder, \& Carroll, 2000).

Social capital has emerged as an important predictor of health and mental health. The construct symbolises the resources available through social networks and supports (Bourdieu, 1986). There are two commonly measured dimensions of social capital: cognitive and structural (De Silva, McKenzie, Harpham, \& Huttly, 2005; Murayama, Fujiwara, \& Kawachi, 2012). Largely motivated by Putnam's (2007) theorising, cognitive social capital refers to beliefs in community trust and social reciprocity, and structural aspects of social capital are related to participation in social groups and organisations. Higher levels of social capital are associated with better physical health (Kim, Subramanian, \& Kawachi, 2008) and mental health (Almedom \& Glandon, 2008; Hall, Bonanno, Bolton, \& Bass, 2014).

A related concept, of particular importance to migrant communities, is the role of social cohesion (Bollen \& Hoyle, 2001; Kawachi \& Berkman, 2000). Social cohesion is defined as ' ... a state of affairs concerning both the vertical and the horizontal interactions among mem- bers of a society, as characterized by a set of attitudes and norms that include trust, a sense of belonging, and the willingness to participate and help, as well as their behavioral manifestations' (Chan, To, \& Chan, 2006, p. 290). One of the most convincing studies showing the beneficial relationship of social cohesion on mental health was conducted with nearly 11,000 people in the United Kingdom. This study showed that neighbourhood social cohesion counteracted economic deprivation to protect against ill mental health (Fone, Dunstan, Llyod, Williams, \& Watkins, 2007). For internal Chinese migrants, living in environments where they feel a low sense of belonging may pose a significant risk to mental health.

According to the conservation of resource (COR) theory (Hobfoll, 1989), people are motivated to obtain and maintain valued resources (self-value, property, social relationships), which aid in survival; lacking valuable resources along with losses or the threat of losses increases stress and leads to poor mental health (Alarcon, Edwards, \& Menke, 2011; Gorgievski \& Hobfoll, 2008; Hall, Murray, Galea, Canetti, \& Hobfoll, 2015; Halbesleben, Neveu, Paustian-Underdahl, \& Westman, 2014; Health, Hall, Canetti, \& Hobfoll, 2013; Hobfoll, 1989). According to the model, resource lack, resource losses or the threat of loss would be a critical source of stress, which may in turn lead to increased depression (Beiter et al., 2015). As social support may be lost during migration, we expect that COR theory can guide our prediction that lacking social support would correlate with depression among migrants. Indeed, previous studies demonstrated that lacking social support was associated with depressive symptoms among migrants (Jaremka et al., 2014). Furthermore, migrants who have social connections and networks with others could prevent depression from negative incidents such as victimisation and social stress (Cheung, 2013, 2014; Teng et al., 2014).

Contrary to the COR model, the 'Healthy Migrant' hypothesis (Abraído-Lanza, Dohrenwend, Ng-Mak, Turner, 1999) holds that those who are able to migrate might be more skilled, healthier and have more family or community support in their migration process. According to this hypothesis, migrants who stay in non-local countries may begin to have similar levels of poor health as the local receiving community (Nolan, 2012). Evidence supporting the Healthy Migrant hypothesis demonstrated that migrants are not more vulnerable compared with nonmigrants (Dai et al., 2015; Leong, Park, \& Kalibatseva, 2013; Lu \& Qin, 2014; Wu \& Schimmele, 2005). One study showed that individuals could choose to migrate or not according to their own will, and showed that migrant status had a positive effect on health (Lu \& Qin, 2014); also, migrants demonstrated a lower risk of developing depression and suicidal thoughts within a year of their migration (Dai et al., 2015).

The current study aimed to establish the relationships between social level risks (social network supports, social capital, and social cohesion) on depressive symptoms 
among migrants and local residents living in Guangzhou, China. Contradictory predictions were made by the COR theory and the Healthy Migrant hypothesis: COR theory suggests that moving to another city might affect people's mental states negatively (Li et al., 2009), while the Healthy Migrant hypothesis predicts better or equal psychological health for migrants compared to native residents (Cheung, 2013; Jin, Wen, Fan, \& Wang, 2012; Li et al., 2007; Wen et al., 2010), at least in the early phase of migration. This study, therefore, is proposed to evaluate the application of the COR theory and the Healthy Migrant hypothesis in Chinese migration.

In the current study, three major hypotheses were made:

1. According to the prediction of the COR theory, we expected that fewer resources would be held within the migrant population than among locals. This relative lack of resources, in turn, would be associated with poorer mental health among migrants compared to non-migrants;

2. Based on the Healthy Migrant hypothesis, however, it was hypothesised that migrants would be less depressed than local residents.

3. We further evaluated whether the time since migration affected the mental health status of migrants, expecting that the longer period of time migrants lived in their new community, the worse depression they would report.

\section{Methods}

\section{Procedure}

The sampling followed a two-step process. We selected Yuexiu and Tianhe, out of the 12 districts of Guangzhou, because of the high proportion of migrants living in the two districts. The population of age 18-59 years old was selected by stratified cluster sampling method within these two districts. Data was collected between May 2014 and October 2014.

Data were collected during household face-to-face interviews, which were conducted by Chinese interviewers using electronic tablet devices. All verbal portions of the interviews were conducted in the participant's Chinese language, either in Mandarin or in Cantonese.

Spatial epidemiological methods were utilised to identify participants. The participants were selected by geographic information systems (GIS), which could randomise and produce the longitude and latitude within the two districts. After selecting the randomised geographic coordinates within the GIS, we used Google Earth images to locate the nearest residential building according to the randomised geographic coordinates. In order to minimise the correlation among participants, only one eligible participant within a household was selected for participation within one building. If there were more than one person within a household eligible for the study, the person with earliest birthday date would be selected for participating the study. For multi-story buildings with multiple households per floor, we randomly selected a floor, and if there was more than one household, we randomly selected a household. The randomisation was done in the field utilising a mobile phone random number generator application. If a potential interviewee in a household refused to participate, or did not have any eligible interviewees in that household, we moved to the next randomised location for no more than three times in total within the same building. If we were refused three times within one building, we moved to another building. We would visit the same household not more than three times if no one responded or the selected individual was not at home. When we were unable to establish contact more than three times within one geographic coordinate, we would mark this coordinate as a non-response. After finishing the study, interviewees were debriefed and received a 50 RMB ( $\sim 8 \mathrm{USD})$ mobile phone prepaid card as compensation for their participation. Both the Institutional Review Board at Guangdong Provincial Skin Diseases and STIs Control Center and University of North Carolina at Chapel Hill approved the study protocol.

\section{Participants}

In total, there were 1,215 attempted surveys, with 14 partial completions, 368 refusals, and 82 uninhabited locations, resulting in a sample of 751 complete surveys and a response rate of $66 \%$. For the present study, we excluded individuals who said they were students, yielding a total sample of 688 participants (383 migrants and 295 nonmigrants).

\section{Measures}

Depression. The Patient Health Questionnaire (PHQ-9; Spitzer, Kroenke, \& Williams, 1999) is a nine-item inventory used to measure depression severity. Participants rated how frequently depressive symptoms occurred in the past 2 weeks. Responses were made on a 4-point Likert scale $(0=$ not at all, $1=$ several days, $2=$ more than half the days, $3=$ nearly every day), and the total score was the sum of all nine items, with higher scores indicating greater depression. The internal reliability of the scale was between 0.86 and 0.89 (Kroenke, Spitzer, \& Williams, 2001). In the current survey, the reliabilities were 0.87 for migrants and 0.88 for non-migrants.

Social resources. For the current study, we utilised seven items from the Social Support Rating Scale (SSRS; Xiao \& Wang, 1999) to measure the social resource dimensions. The original SSRS is a 10-item inventory that measures three aspects of social support: subjective support (emotional support), objective support (financial help) and support-seeking behavior (active or passive). The scale has high reported internal reliability of 0.92 (Xiao \& Yang, 1987). 
Table 1

Independent Samples $t$ Test Results for Differences Between Migrants and Non-Migrants Social Resource Characteristics

\begin{tabular}{|c|c|c|c|c|c|c|}
\hline \multirow[b]{2}{*}{ Variable } & \multicolumn{2}{|c|}{ Migrant } & \multicolumn{2}{|c|}{ Non-migrant } & \multirow[b]{2}{*}{$t$ test } & \multirow[b]{2}{*}{ Cohen's o } \\
\hline & $M$ & $S D$ & $M$ & $S D$ & & \\
\hline Community belonging & 3.51 & 0.79 & 3.90 & 0.67 & $6.84^{* * *}$ & .53 \\
\hline Friendship network & 1.93 & 0.90 & 2.01 & 0.83 & -1.22 & .09 \\
\hline Neighbour relationship & 1.30 & 1.21 & 1.55 & 1.11 & $-2.81^{* *}$ & .22 \\
\hline Colleague relationship & 2.09 & 0.99 & 2.29 & 0.83 & $-2.77^{* *}$ & .22 \\
\hline Family support & 9.49 & 3.85 & 9.80 & 4.03 & -1.02 & .08 \\
\hline Financial support & 2.68 & 1.46 & 2.87 & 1.59 & -1.64 & .12 \\
\hline Emotional support & 2.96 & 1.52 & 3.42 & 1.58 & $-3.85^{* * *}$ & .30 \\
\hline Community activities & 1.00 & 0.87 & 1.25 & 0.86 & $-3.78^{* * *}$ & .29 \\
\hline Depression & 2.92 & 3.88 & 2.99 & 3.95 & -0.23 & .02 \\
\hline
\end{tabular}

Note: $M=$ mean, $S D=$ standard deviation, Cohen's $d: 0.20=$ small effect, $0.50=$ medium effect, $0.80=$ large effect.

${ }^{* *} p<.01 .{ }^{* * *} p<.001$.

Social network supports: Friends. One item assessed the total number of friendship social network supports $(0=$ none, $1=1-2,2=3-5,4=>6$ ).

Social network supports: Emotional. One item measured the total number of sources of emotional support (e.g., from friends, family members, colleagues range $0-7$ ).

Social network supports: Financial. One item measured the number of available financial supports (e.g., from friends, family members, colleagues; range 0-7).

Relationship quality. Two items measured the closeness of the relationship with (1) neighbors and (2) colleagues (scored from 1 to 4 ).

Family emotional support quality. One item measured the quality of emotional support from family members (rated from $0=$ none, to $3=$ high; range $0-15$ ).

Structural social capital. Joining community activities (rated from $0=$ never to $4=$ actively participate).

Community belonging (social cohesion). In addition, we added one item to evaluate community belonging, an aspect of social cohesion (Bollen \& Hoyle, 2001; Chan et al., 2006; Kawachi \& Berkman, 2000) with the extent of agreeing to the item 'I feel welcome here in Guangzhou by the people who live here' (scored from $1=$ strongly disagree to $5=$ strongly agree).

Sample characteristics. Data on participant characteristics were obtained for age, biological sex, marital status, education level, personal income, employment status (0 $=n o, 1=y e s)$, the length of time living in Guangzhou ( 0 $=$ less than one year, $1=$ one year or longer), and migrant status (location of their hukou, and permanent household registration).

\section{Analysis}

We first examined the bivariate differences between migrants and non-migrants with regard to their social resources, depression severity, and participant characteristics using independent sample $t$ tests and chi-square tests. Effect sizes for the mean differences were established using Cohen's $d$, and interpreted such that $0.20=$ small effect, $0.50=$ medium effect, $0.80=$ large effect (Cohen, 1992).
We next stratified correlational and hierarchical multiple variable regression analyses to assess correlates of depression for migrants and non-migrants separately. Our regression analysis proceeded such that in the first block we included demographic characteristics that were theoretically related to depression and social resources, which might confound the association between social resources and depression. In the second block we included the social resource variables. We interpreted the change in model $R^{2}$ to indicate the increase in variance explained by the addition of social resources to the model. We conducted preliminary analysis to insure that our regression estimates were not influenced by multicolinearity. The variance inflation factors (VIF) for the models were below critical values indicating multicolinearity was not a significant concern in our analyses (individual VIF all lower than 1.7 and mean VIF was 1.3 for migrants and non-migrant models.).

\section{Results}

$T$-test results (see Table 1) between migrant and nonmigrant groups for social resource characteristics and depression showed significant differences in community belonging (i.e., social cohesion); (migrant: $n=386, M=$ 3.51, $S D=0.79$; non-migrant: $n=291, M=3.90, S D=$ $0.68), t(675)=-6.89, p<.001$, Cohen's $d=.53$; neighbour relationship quality (migrant: $n=384, M=1.30$, $S D=1.21$; non-migrant: $n=297, M=1.56, S D=1.11$ ), $t(679)=-2.94, p<.01$, Cohen's $d=.22$; colleagues' relationship quality (migrant: $n=380, M=2.1, S D=.99$; non-migrant: $n=292, M=2.30, S D=.83), t(670)=$ $-2.76, p<.01$, Cohen's $d=.22$; emotional support from family (migrant: $n=391, M=2.94, S D=1.54$; nonmigrant: $n=297, M=3.41, S D=1.59), t(686)=-3.85$, $p<.001$, Cohen's $d=.31$; and joining community activities (migrant: $n=387, M=1.00, S D=.87$; non-migrant: $n=296, M=1.25, S D=.86), t(681)=-3.78, p<.001$, Cohen's $d=.29$. No significant differences, however, were found in friend social network size (migrant: $n=388, M$ $=1.93, S D=0.90$; non-migrant: $n=297, M=2.01, S D=$ $0.83), t(683)=-1.20, p=.23$, Cohen's $d=.09$; financial 
Table 2

Correlation Matrix for Demographics, Depression, and Social Support Variables Among Migrants $(n=352)$

\begin{tabular}{|c|c|c|c|c|c|c|c|c|c|c|c|c|}
\hline & 1 & 2 & 3 & 4 & 5 & 6 & 7 & 8 & 9 & 10 & 11 & 12 \\
\hline 1. Depression & - & & & & & & & & & & & \\
\hline 2. Age & $-0.12^{*}$ & - & & & & & & & & & & \\
\hline 3. Education & 0.09 & $-0.45^{* *}$ & - & & & & & & & & & \\
\hline 4. Income & -0.01 & $-0.07^{*}$ & $0.21^{* *}$ & - & & & & & & & & \\
\hline 5. Community belonging & $-0.15^{* *}$ & -0.03 & 0.08 & $-0.11^{*}$ & - & & & & & & & \\
\hline 6. Friend network size & 0.03 & $-0.19 * * *$ & $0.31 * * *$ & $0.10 *$ & $-0.11^{*}$ & - & & & & & & \\
\hline 7. Neighbour relationship & -0.07 & $0.20 * * *$ & $-0.13^{*}$ & -0.01 & $0.14^{* *}$ & 0.03 & - & & & & & \\
\hline 8. Colleague relationship & -0.04 & -0.05 & 0.12 & 0.05 & $0.21 * * *$ & $0.22 * * *$ & $0.40 * * *$ & - & & & & \\
\hline 9. Family support & $-0.12^{*}$ & $0.32^{* * *}$ & $-0.22 * * *$ & 0.04 & 0.10 & -0.04 & $0.15^{* *}$ & 0.04 & - & & & \\
\hline 10. Financial support & 0.03 & -0.06 & $0.11^{*}$ & 0.03 & 0.03 & $0.24^{* * *}$ & 0.06 & $0.17^{* * *}$ & $0.20 * * *$ & - & & \\
\hline 11. Emotional support & 0.06 & 0.05 & $0.12^{*}$ & -0.02 & -0.02 & $0.21 * * *$ & 0.06 & $0.12^{*}$ & $0.29 * * *$ & $0.64 * * *$ & - & \\
\hline 12. Community activity & 0.03 & $-0.17^{* *}$ & $0.21 * * *$ & 0.03 & 0.10 & $0.17^{* * *}$ & 0.10 & $0.27^{* * *}$ & 0.04 & $0.11 *$ & $0.15^{* *}$ & - \\
\hline
\end{tabular}

Note: ${ }^{*} p<.05 .^{* *} p<.01{ }^{* * *} p<.001$.

Table 3

Correlation Matrix for Demographics, Depression, and Social Support Variables Among Non-Migrants $(n=273)$

\begin{tabular}{|c|c|c|c|c|c|c|c|c|c|c|c|c|}
\hline & 1 & 2 & 3 & 4 & 5 & 6 & 7 & 8 & 9 & 10 & 11 & 12 \\
\hline 1. Depression & - & & & & & & & & & & & \\
\hline 2. Age & $-0.21^{* * *}$ & - & & & & & & & & & & \\
\hline 3. Education & 0.03 & $-0.44^{* * *}$ & - & & & & & & & & & \\
\hline 4. Income & -0.03 & -0.05 & $0.17^{* *}$ & - & & & & & & & & \\
\hline 5. Community belonging & 0.06 & 0.08 & 0.02 & -0.00 & - & & & & & & & \\
\hline 6. Friend network size & $-0.15^{*}$ & $-0.15^{* * *}$ & $0.29 * * *$ & 0.06 & -0.02 & - & & & & & & \\
\hline 7. Neighbur relationship & -0.12 & $0.17^{* * *}$ & $-0.12^{*}$ & -0.05 & 0.11 & $0.15^{* *}$ & - & & & & & \\
\hline 8. Colleague relationship & -0.01 & 0.00 & 0.10 & -0.04 & 0.04 & $0.25^{* * *}$ & $0.36 * * *$ & - & & & & \\
\hline 9. Family support & $-0.17^{* *}$ & $0.39 * * *$ & -0.10 & -0.09 & 0.08 & 0.08 & $0.19 * *$ & $0.15^{*}$ & - & & & \\
\hline 10. Financial support & -0.02 & -0.03 & $0.13^{*}$ & 0.03 & 0.03 & $0.26^{* * *}$ & 0.09 & $0.19^{* *}$ & $0.25^{* * *}$ & - & & \\
\hline 11. Emotional support & -0.08 & -0.04 & $0.17^{* *}$ & 0.02 & 0.05 & $0.27^{* * *}$ & $0.15^{*}$ & $0.22^{* * *}$ & $0.28 * * *$ & $0.59 * * *$ & - & \\
\hline 12. Community activity & -0.07 & $-0.13^{*}$ & $0.20 * * *$ & 0.04 & 0.01 & $0.17^{* *}$ & $0.23^{* * *}$ & $0.23^{* * *}$ & 0.06 & 0.07 & $0.15^{*}$ & - \\
\hline
\end{tabular}

Note: ${ }^{*} p<.05 .{ }^{* *} p<.01{ }^{* * *} p<.001$.

support network (migrant: $n=391, M=2.66, S D=1.48$; non-migrant: $n=297, M=2.87, S D=1.60), t(686)=$ $-1.77, p=.08$, Cohen's $d=.19$ and depressive symptoms (migrant: $n=383, M=2.92, S D=3.88$; non-migrant: $n=295, M=2.99, S D=3.95), t(676)=-0.23, p=.82$, Cohen's $d=.02$, between the two groups.

Sample characteristics that differed between the two groups included age (migrant: $n=386, M=31.09$, $S D=9.52$; non-migrant: $n=296, M=38.32, S D=$ $10.98), t(680)=-9.20, p<.001$, Cohen's $d=.70$; personal income (migrant: $n=384, M=4650.91, S D=$ 6833.49; non-migrant: $n=288, M=7015.13, S D=$ 14896.95), $t(670)=-2.75, p<.01$; sex, $\chi^{2}(d f=1)=$ $8.33, p=.004,45.43 \%$ of migrants were women compared to $56.61 \%$ non-migrants; marital status, $\chi^{2}(d f=1)$ $=18.99, p<.0001,62.30 \%$ of migrants were married or cohabitating compared to $77.98 \%$ of non-migrants; educational status, $\chi^{2}(d f=1)=65.70, p<.0001,63.87 \%$ of migrants had at least junior high school or above, compared to $90.85 \%$ of non-migrants; length of time living in Guangzhou (Fisher's exact test, $p<.0001$ ), 12.01\% of migrants lived in Guangzhou less than one year compared to just $0.34 \%$ of non-migrants. No differences were noted with regard to employment status, $\chi^{2}(d f=1)=0.49, p=$ .48 , as $87.70 \%$ of migrants and $85.82 \%$ of non-migrants reported being employed; and, ethnicity, $\chi^{2}(d f=1)=$ $0.48, p=.49$, with $97.07 \%$ of migrants and $97.93 \%$ of non-migrants reported being Han Chinese.

The results of stratified correlation analyses on all study variables are presented in Table 2 and Table 3 . The results show that in the migrant group age $(r=-0.12, p<$ $.05)$, community belonging $(r=-0.15, p<.01)$ and family support $(r=-0.12, p<.05)$ were significantly and negatively correlated with depressive symptoms, whereas in the non-migrant group, age $(r=-0.207, p<.001)$, family support $(r=-0.17, p<.01)$, and social network size $(r=-0.144, p<.05)$ was significantly and negatively correlated with depressive symptoms.

Regression analyses stratified by migration status demonstrated that depression was predicted by different risk factors for migrants and local residents (see Table 4). In the migrant group, the first model block including only demographic characteristics were significant, but no individual variable was significant. In the second block, community belonging (i.e., social cohesion) significantly predicted decreased depressive symptoms, $\beta=-0.79, p<.01$. This means that for every one unit increase in community belonging, migrant depression decreased by .79 points. A significant increase in the $R^{2}$ model indicated that social resources uniquely contributed .044 to the variance 
Table 4

Regression Analyses for Variables Predicting Migrants' and Non-Migrants' Depression

\begin{tabular}{|c|c|c|c|c|c|c|}
\hline \multirow[b]{2}{*}{ Variable } & \multicolumn{3}{|c|}{ Migrant $(n=358)$} & \multicolumn{3}{|c|}{ Non-migrant $(n=283)$} \\
\hline & $\underline{B}$ & $S E$ & $t$ & B & $S E$ & $t$ \\
\hline \multicolumn{7}{|l|}{ Step 1} \\
\hline Sex & 0.19 & 0.41 & 0.45 & .11 & .48 & 0.25 \\
\hline Age & -0.04 & 0.02 & -1.81 & -.08 & 0.02 & $-3.52^{* *}$ \\
\hline Education & 0.14 & 0.17 & 0.80 & -.26 & 0.24 & -0.30 \\
\hline Ethnicity (Han) & -0.21 & 1.19 & -0.18 & -2.20 & 1.78 & -1.24 \\
\hline Length of time in Guangzhou & -0.38 & 0.62 & -0.60 & -1.98 & 4.32 & -0.46 \\
\hline $\mathrm{F}$ (model) & \multicolumn{3}{|c|}{$5,352=1.32, p=.26$} & \multicolumn{3}{|c|}{$5,277=3.06, p=.01$} \\
\hline Model $R^{2}$ & & & 0.018 & & & 0.052 \\
\hline \multicolumn{7}{|l|}{ Step 2} \\
\hline Community belonging & -0.79 & 0.27 & $-2.93^{* *}$ & 0.55 & 0.35 & 1.56 \\
\hline Friend network size & 0.20 & 0.25 & 0.78 & -0.71 & 0.32 & $-2.25^{*}$ \\
\hline Neighbour relationship & -0.08 & 0.19 & -0.44 & -0.34 & 0.24 & -1.48 \\
\hline Colleague relationship & -0.11 & 0.24 & -0.46 & 0.41 & 0.32 & 1.28 \\
\hline Family support & -0.10 & 0.06 & -1.62 & -0.09 & 0.07 & -1.31 \\
\hline Financial support & -0.03 & 0.18 & -0.17 & 0.16 & 0.18 & 0.87 \\
\hline Emotional support & 0.21 & 0.18 & 1.16 & -0.13 & 0.19 & -0.71 \\
\hline Community activities & 0.09 & 0.25 & 0.35 & -0.31 & 0.29 & -1.05 \\
\hline$\overline{\mathrm{F} \text { (model) }}$ & \multicolumn{3}{|c|}{$13,344=1.76, p<.05$} & \multicolumn{3}{|c|}{$13,269=2.45, p<.001$} \\
\hline Model $R^{2}$ & \multirow{2}{*}{\multicolumn{3}{|c|}{$8344-201 n-062$}} & \multicolumn{3}{|c|}{0.106} \\
\hline $\mathrm{F}\left(\Delta R^{2}\right)$ & \multicolumn{2}{|c|}{$8,344=2.01, p<.05$} & & \multicolumn{3}{|c|}{$8,269=2.02, p<.05$} \\
\hline$\Delta R^{2}$ & \multicolumn{3}{|c|}{.044} & \multicolumn{3}{|c|}{0.054} \\
\hline
\end{tabular}

Note: $B=$ beta coefficient. $S E=$ standard error. ${ }^{*} p<.05 .{ }^{* *} p<.01$

explained in migrant depression. The overall $R^{2}$ model was .062.

For the non-migrant group, in the first block, age ( $\beta=$ $-0.08, p<.01)$ was significantly and negatively associated with decreased depression symptoms. In the second block, social network size $(\beta=-0.71, p<.05)$ was significantly and negatively associated with depressive symptoms. Together, these findings suggest that for every one year increase in age, and for every one unit increase in friend social network, non-migrant depression decreased by .08 and .71 points respectively. A significant increase in the $R^{2}$ model indicated that social resources uniquely contributed .054 to the variance explained in non-migrant depression. The overall $R^{2}$ model was 0.106 .

\section{Discussion}

The current analysis was designed to evaluate dimensions of social resources (social networks, relationship quality, emotional support, structural social capital and community belonging), on depressive symptoms for migrants and non-migrants in mainland China. Face-to-face interviews were conducted in two districts in Guangzhou. Based on two paradoxical theories, the COR theory and the Healthy Migrant hypothesis, we tested three possible hypotheses in our analysis: (1) according to the prediction of COR theory, we expected that fewer social resources would be held by migrants compared to local residents, and lacking these resources would be associated with greater depressive symptoms; (2) based on the Healthy Migrant hypothesis, however, it was hypothesised that migrants would be less depressed than locals; and, finally, that (3) the time spent living in Guangzhou would be associated with increased depression among migrants.

Our data indicated a significant relative lack in nearly all social resources among the migrants, specifically including community belonging (i.e., social cohesion), closeness with neighbours and colleagues, number of available family emotional supports, and structural social capital (joining in community activities). The lack of community belonging was associated with poorer mental health among migrants, consistent with our predictions based on COR theory (Hobfoll, 1989). However, the other social resources we examined were not associated with depression.

Further, we found that depressive symptoms for migrants and non-migrants were associated with different protective factors. For the migrants, the lack of community belonging could increase the chance of being depressed, which is consistent with previous research studies (Dalgard \& Thapa, 2007; Reblin \& Uchino, 2008). One reason might be that if a migrant could not integrate with the existing communities, he/she will feel isolated and his/her social needs will not be met. Wang and Fan (2012) showed that migrants who did not possess a resident hukou felt inferior and tended to identify less with the group than others. These social factors, in turn, are associated with poorer mental health among migrants (Sani, Herrera, Wakefield, Boroch, \& Gulyas, 2012).

For local residents, their friendship social network was protective against depressive symptoms. Having larger friendship networks for local residents may indicate their positive ability to develop and maintain social bonds, which confers mental health benefits. For local residents, 
a sense of belonging in their community may be less salient than for migrants, since local residents are from Guangzhou and are not attempting to adjust to a new social environment. Older age was also protective against depression symptoms among non-migrants. This is consistent with studies showing an onset of depression among younger adults (Kessler, Berglund, Demler, Jin, Merikangas, \& Walters, 2005) and the older age of the non-migrant participants in the current study.

Depression was not significantly different between migrants and local residents. This partially supports the Healthy Migrant hypothesis, suggesting that migrant communities are equally healthy, or in some cases, more healthy than people living in the local communities that receive them. Previous studies showed that in some cases, migrants who have a rural hukou and lower social affiliation do not necessarily have higher stress level (Chen, 2011). We attempted to also account for length of time in Guangzhou as a possible key factor that would increase depressive symptoms. However, the present study found no differences between migrants who had lived in Guangzhou over one year than to those who were newly arrived.

The results of our study seem to be contradictory to previous large-scale studies done in China that suggested migrants were more vulnerable to depression than nonmigrants (Lu et al., 2012; Mou et al., 2011; Qiu et al., 2011). Our data, however, found that the migrants and non-migrants generally did not differ in depressive symptoms even though they had received significantly different levels of social support and resources. There are several possible explanations for this result. First, previous studies utilised convenience samples of the most at-risk migrant communities whereas the current study utilised a population representative sampling approach. Relatedly, previous studies targeted rural-to-urban migrants (Lu et al., 2012; Mou et al., 2011; Qiu et al., 2011), while the present study was conducted in areas with a high proportion of migrants without emphasising the specific type of migrants studied. Second, different scales were used to measure depression in the current study. Previous studies commonly used the Center for Epidemiologic Studies Depression Scale (Lu et al., 2012; Mou et al., 2011; Qiu et al., 2011), while The Patient Health Questionnaire measures specific diagnostic symptoms of depression, was used in the current study.

In terms of practical implications, our study results imply that clinicians might consider adjusting their approach to treatment according to the migrant status of the patient. Social support interventions, including group interventions with social skill training and social support provision, and individual interventions with self-help and peers (Hogan, Linden, \& Najarian, 2002), might be worthwhile. Moreover, dyadic interventions, social network interventions, mutual aid groups, and community interventions (Hernández-Plaza, Alonso-Morillejo, \& PozoMuñoz, 2006) might be considered. These intervention programs might be able to help new migrants gain support from others, and hence increase their social resources, in order to ease their stress integrating with the community. For local residents, interventions that enhance social support networks may be beneficial, as this was a key determinant of lower depression scores in this sample.

Results of the previous studies on social support interventions provided evidence for its possible adaptation in China (Hernández-Plaza et al., 2006; Hogan et al., 2002). Intergroup interventions that can encourage migrant integration within host communities are indicated. These interventions may involve intergroup contact or public messaging that highlights the important economic and social contributions migrants make in their receiving communities. However, it may not be local residents who provide the best chance of finding a supportive home in their new city. Fostering social bonds and cohesion within newcomer communities might prove most useful to protect mental health (Veling et al., 2009).

\section{Limitations}

There were several limitations in this study. First, as it was a cross-sectional, it was not possible to conclude any clear causal relationship between the variables. Indeed, studies have emerged that demonstrate the dynamic nature of social resource variables and their associations with mental health (Hall et al., 2014; Hall, Tol, Jordans, Bass, \& de Jong, 2014). Therefore, a longitudinal study addressing a similar topic should be carried out in future. Moreover, participants may under-report their symptoms due to fear of stigma. The current study focused on local Chinese and internal Chinese migrants, so the results might not be able to be generalised to other migrant communities, including international migrants. We also acknowledge the limitation of using a single-item indicator to measure belonging (i.e., social cohesion), which can naturally limit reliability. Future studies should utilise a more robust measurement of this construct.

In conclusion, limited findings are reported for classifying risk or protective factors among internal migrants in China (Lu \& Qin, 2014; Qiu et al., 2011), so additional research on this issue is warranted. This study aimed to identify different factors that may affect the mental health status among Chinese with different migrant status. The current results suggest that migrant social cohesion is an important social-level target for community intervention.

\section{Declaration of Interest}

The authors declare no conflicts of interest.

\section{Acknowledgments}

This project was funded by the Fogarty Global Health Fellows Program Consortium comprised of the University of North Carolina, John Hopkins Bloomberg School of Public Health, Morehouse and Tulane (5R25TW009340-02, 1R25TW009340-01, awarded to Hall and Chen). Dr Hall received additional support from grant SRG2014-00001FSS awarded by the R\&DAO, University of Macau, and 
Mr Hoi received funding from the University of Macau R\&DAO Summer Research Experience Program to participate in study data collection and study management. This current analysis is a result of Mr Hoi's undergraduate thesis and he presented portions of this work at the Association of Regional Union of Psychological Science Conference in Singapore in March 2015. We thank the Faculty of Social Sciences, University of Macau for providing funding to attend the conference. We thank all the study participants and the team of interviewers from Sun Yat-sen University and the University of Macau. Finally, we thank Professor Carl Latkin, PhD, for his comments on an earlier draft of this manuscript.

\section{References}

Abraído-Lanza, A.F., Dohrenwend, B.P., Ng-Mak, D.S., \& Turner, J.B. (1999). The Latino mortality paradox: A test of the 'salmon bias' and healthy migrant hypotheses. American Journal of Public Health, 89, 1543-1548.

Alarcon, G.M., Edwards, J.M., \& Menke, L.E. (2011). Student burnout and engagement: A test of the conservation of resources theory. The Journal of Psychology: Interdisciplinary and Applied, 145, 211-227.

Almedom, A.M., \& Glandon, D. (2008). Social capital and mental health: An updated interdisciplinary review of primary evidence. In I. Kawachi, S.V. Subramanian, \& D. Kim (Eds.), Social capital and health (pp. 191-214). New York, NY: Springer.

Beiter, R., Nash, R., McCrady, M., Rhoades, D., Linscomb, M., Clarahan, M., \& Sammut, S. (2015). The prevalence and correlates of depression, anxiety, and stress in a sample of college students. Journal of Affective Disorder, 173, 90-96.

Bollen, K.A., \& Hoyle, R.H. (2001). Perceived cohesion: a conceptual and empirical examination. Social Forces, 69, 479-504.

Bourdieu, P. (1986). The forms of capital. In J. Richardson (Ed.), Handbook of theory and research for the sociology of education (pp. 241-258). New York, NY: Greenwood.

Caplan, G. (1974). Support systems and community mental health. New York: Behavioral Publications.

Chan, K.W., \& Buckingham, W. (2008). Is China abolishing the hukou system? The China Quaterly, 195, 582-605.

Chan, J., To, H. \& Chan, E. (2006). Reconsidering social cohesion: developing a definition and analytical framework for empirical research, Social Indicators Research, 75, 273-302.

Chen, J. (2011). Internal migration and health: Re-examining the health migrant phenomenon in China. Social Science \& Medicine, 72, 1294-1301.

Chen, X., Cheng, H.G., Huang, Y., Liu, Z., \& Luo, X. (2012). Depression symptoms and chronic pain in the community population in Beijing, China. Psychiatry Research, 200, 313317.

Cheung, N.W.T. (2013). Rural-to-urban migrant adolescents in Guangzhou, China: Psychological health, victimization, and local and trans-local ties. Social Science \& Medicine, 93, 121129.
Cheung, N.W.T. (2014). Social stress, locality of social ties and mental well-being: The case of rural migrant adolescents in urban China. Health \& Place, 27, 142-154.

Cohen, J. (1992). A power primer. Psychological Bulletin, 112, 155-159.

Dai, J., Zhong, B., Xiang, Y., Chiu, H.F.K., Chan, S.S.M., Yu, X., \& Caine, E.D. (2015). Internal migration, mental health, and suicidal behaviors in young rural Chinese. Social Psychiatry and Psychiatric Epidemiology, 50, 621-631.

Dalgard, O.S., \& Thapa, S.B. (2007). Immigration, social integration and mental health in Norway, with focus on gender differences. Clinical Practice and Epidemiology in Mental Health, 3, 24.

De Silva, M.J., McKenzie, K., Harpham, T., \& Huttly, S.R.A. (2005). Social capital and mental illness: A systematic review. Journal of Epidemiology and Community Health, 59, 619-627. doi:10.1136/jech.2004.029678

Fone, D., Dunstan, F., Llyod, K., Williams, G., \& Watkins, J. (2007). Does social cohesion modify the association between area income deprivation and mental health? A multilevel analysis, International Journal of Epidemiology, 36, 338345.

Gorgievski, M.J., \& Hobfoll, S. (2008). Work can burn us out or fire us up: Conservation of resources in burnout and engagement In J.R.B. Halbesleben (Ed.), Handbook of stress and burnout in health care (pp. 1-17). Hauppauge, NY: Nova Science Publishers.

Gu, L., Xie, J., Long, J., Chen, Q., Chen, Q., Pan, R., ... Su, L. (2013). Epidemiology of major depressive disorder in mainland China: A systematic review. PLoS One, 8, e65356.

Hall, B.J., Murray, S.M., Galea, S., Canetti, C., \& Hobfoll, S.E. (2015). Examining predictors of incident posttraumatic stress disorder during ongoing political violence within the Palestinian Authority. Social Psychiatry and Psychiatric Epidemiology, 15, 561-568.

Hall, B.J., Bonanno, G.A., Bolton, P., \& Bass, J.K. (2014). A longitudinal investigation of changes in social resources associated with psychological distress among Kurdish torture survivors living in Northern Iraq. The Journal of Traumatic Stress, 27, 446-453.

Hall, B.J., Tol, W., Jordans, M., Bass, J., \& Jong, J. (2014). Understanding resilience in armed conflict: Social resources and mental health of children in Burundi. Social Science and Medicine, 114, 121-128.

Hall, B.J., Bolton, P., Annan, J., Kaysen, D., Robinette, K., Certinoglu, T., Wachter, K., \& Bass, J. (2014). The effect of cognitive therapy on structural social capital: Results from a randomized controlled trial among sexual violence survivors in the Democratic Republic of Congo. American Journal of Public Health, 104, 1680-1686.

Halbesleben, J.R.B., Neveu, J., Paustian-Underdahl, S.C., \& Westman, M. (2014). Getting to the 'COR': Understanding the role of resources in conservation of resources theory. Journal of Management, 40, 1334-1364.

Heath, N., Hall, B.J., Canetti, D., \& Hobfoll, S.E. (2013). Exposure to political violence, psychological distress, resource loss, and benefit finding as predictors of domestic conflict 
among Palestinians. Psychological Trauma: Theory, Research, Practice, and Policy, 5, 366-376.

Hernández-Plaza, S., Alonso-Morillejo, E., \& Pozo-Muñoz, C. (2006). Social support interventions in migrant populations. British Journal of Social Work, 36, 1151-1169.

Hobfoll, S. (1989). Conservation of resources: A new attempt at conceptualizing stress. American Psychologist, 44, 513-524.

Hogan, B.E., Linden, W., \& Najarian, B. (2002). Social support interventions: Do they work? Clinical Psychology Review, 22, 383-442.

Ismayilova, L., Lee, N.H., Shaw, S., El-Bassel, N., Gilbert, L., Terlikbayeva, A., \& Rozental, Y. (2014). Mental health and migration: Depression, alcohol abuse, and access to health care among migrants in central Asia. Journal of Immigrant and Minority Health, 16, 1138-1148.

Kawachi, I., \& Berkman, L. (2000). Social cohesion, social capital, and health. In I. Kawachi \& L. Berkman (Eds.), Social epidemiology (pp. 184-185). New York: Oxford University Press.

Kim, D., Subramanian, S. V., \& Kawachi, I. (2008). Social capital and physical health: A systematic review of the literature. In I. Kawachi, S.V. Subramanian, \& D. Kim (Eds.), Social capital and health (pp. 139-190). New York: Springer.

Jaremka, L.M., Andridge, R.R., Fagundes, C.P., Alfano, C.M., Povoski, S.P., Lipari, A.M., ... Kiecolt-Glaser, J.K. (2014). Pain, depression, and fatigue: Loneliness as a longitudinal risk factor. Health Psychology, 33, 948-957.

Jin, L., Wen, M., Fan, J.X., \& Wang, G. (2012). Trans-local ties, local ties and psychological well-being among rural-to-urban migrants in Shanghai. Social Science \& Medicine, 75, 288296.

Kessler, R.C., Berglund, P., Demler, O., Jin, R., Merikangas, K.R., \& Walters, E.E. (2005). Lifetime prevalence and age-of-onset distributions of DSM-IV disorders in the National Comorbidity Survey Replication. Archives of General Psychiatry, 62, 593-602.

Kroenke, K., Spitzer, R.L., \& Williams, J.B. (2001). The PHQ9: validity of a brief depression severity measure. Journal of General Internal Medicine, 16, 606-613.

Lee, S., Tsang, A., Zhang, M., Huang, Y., He, Y., Liu, Z., ... Kessler, R.C. (2007). Lifetime prevalence and inter-cohort variation in DSM-IV disorders in metropolitan China. Psychological Medicine, 37, 61-71.

Lee, S., Tsang, A., Huang, Y., He, Y., Liu, Z., Zhang, M., ... Kessler, R.C. (2009). The epidemiology of depression in metropolitan China. Psychological Medicine, 39, 735-747.

Leong, F., Park, Y.S., \& Kalibatseva, Z. (2013). Disentangling immigrant status in mental health: Psychological protective and risk factors among Latino and Asian American immigrants. American Journal of Orthopsychiatry, 83, 361-371.

Li, K., Cui, Z., Cui, L., Jiang, Q., Shi, G., Wu, H., ... Zhao, E. (2008). Epidemiological survey of mental disorders in the people aged 18 and older in Hebei province. Asian Journal of Psychiatry, 1, 51-55.

Li, L., Wang, H., Ye, X., Jiang, M., Lou, Q., \& Hesketh, T. (2007). The mental health status of Chinese rural-urban mi- grant workers: Comparison with permanent urban and rural dwellers. Social Psychiatry and Psychiatric Epidemiology, 42, 716-722.

Li, X., Stanton, B., Fang, X., \& Lin, D. (2006). Social stigma and mental health among rural-to-urban migrants in China: A conceptual framework and future research needs. World Health \& Population, 8, 14-31.

Li, X., Stanton, B., Fang, X., Xiong, Q., Yu, S., Lin, D., .. . Wang, B. (2009). Mental health symptoms among rural-to-urban migrants in China: A comparison with their urban and rural counterparts. World Health \& Population, 11, 15-29.

Lin, D., Li, X., Wang, B., Hong, Y., Fang, X., Qin, X., \& Stanton, B. (2011). Discrimination, perceived social inequity, and mental health among rural-to-urban migrants in China. Community Mental Health Journal, 47, 171-180.

Lu, Y., Hu, P., \& Treiman, D.J. (2012). Migration and depressive symptoms in migrant-sending areas: Findings from the survey of internal migration and health in China. International Journal of Public Health, 57, 691-698.

Lu, J., Ruan, Y., Huang, Y., Yao, J., Dang, W., \& Gao, C. (2008). Major depression in Kunming: Prevalence, correlates and co-morbidity in a south-western city of China. Journal of Affective Disorders, 111, 221-226.

Lu, Y., \& Qin, L. (2014). Healthy migrant and salmon bias hypotheses: A study of health and internal migration in China. Social Science \& Medicine, 102, 41-48.

Ma, X., Xiang, Y., Cai, Z., Li, S., Xiang, Y., Guo, H., ... Ungvari, G.S. (2009). Prevalence and socio-demographic correlates of major depressive episode in rural and urban areas of Beijing, China. Journal of Affective Disorders, 115, 323-330.

Mou, J., Cheng, J., Griffiths, S.M., Wang, S.Y.S., Hiller, S., \& Zhang, D. (2011). Internal migration and depressive symptoms among migrant factory workers in Shenzhen, China. Journal of Community Psychology, 33, 212-230.

Murayama, H., Fujiwara, Y., \& Kawachi, I. (2012). Social capital and health: A review of prospective multilevel studies. Journal of Epidemiology, 22, 179-187.

Nolan, A. (2012). The 'healthy immigrant' effect: Initial evidence from Ireland. Health Economics, Policy and Law, 7, 343362.

Putnam, R.D. (2007). E Pluribus Unum: Diversity and community in the twenty-first century. The 2006 Johan Skytte Prize Lecture, Scandinavian Political Studies, 30, 137-174.

Qiu, P., Caine, E., Yang, Y., Chen, Q., Li, J., \& Ma, X. (2011). Depression and associated factors in internal migrant workers in China. Journal of Affective Disorders, 134, 198207.

Reblin, M., \& Uchino, B.N. (2008). Social and emotional support and its implication for health. Current Opinion in Psychiatry, 21, 201-205.

Sani, F., Herrera, M., Wakefield, J.R.H., Boroch, O., \& Gulyas, C. (2012). Comparing social contact and group identification as predictor of mental health. British Journal of Social Psychology, 51, 781-790.

Spitzer, R., Kroenke, K., \& Williams, J. (1999). Validation and utility of a self-report version of PRIME-MD: the PHQ 
primary care study. Journal of the American Medical Association, 282, 1737-1744.

Teng, P., Hall, B.J., \& Li, L. (2014). The association between social resources and depression among female migrants affected by domestic violence. European Journal of Psychotraumatology, 5. doi:10.3402/ejpt.v5.26528

Van den Akker-Scheek, I., Stevens, M., Spriensma, A., \& van Horn, J.R. (2004). Groningen Orthopaedic Social Support Scale: Validity and reliability. Journal of Advanced Nursing, 47, 57-63.

Veling, W., Hoek, H., Wiersma, D., \& Mackenbach, J. (2009). Ethnic identity and the risk of schizophrenia in ethnic minorities: A case-control study. Schizophrenia Bulletin, 36, $1149-1156$.

Wang, W.W., \& Fan, C.C. (2012). Migrant workers' integration in urban China: Experiences in employment, social adaptation, and self-identity. Eurasian Geography and Economics, $53,731-749$.

Wei, B., Chen, Q., Feng, Q., Pang, R., Chen, Q., Huang, G., .. Li, H. (2010). Epidemiological survey of mental disorders in urban and rural in Guangxi Zhuang Autonomous Region, China. Journal of Guangxi Medical University, 27, 951-956.

Wen, M., Fan, J., Jin, L., \& Wang, G. (2010). Neighborhood effects on health among migrants and natives in Shanghai, China. Health \& Place, 16, 452-460.

Whittmore, R., Rankin, S.H., Callahan, C.D., Leder, M.C., \& Carroll, D.L. (2000). The peer advisor experience providing social support. Qualitative Health Research, 10, 260276.
Wong, D.F.K., He, X., Leung, G., Lau, Y., \& Chang, Y. (2008). Mental health of migrant workers in China: Prevalence and correlates. Social Psychiatry and Psychiatric Epidemiology, 43, 483-489.

Wu, X., \& Treiman, D.J. (2004). The household registration system and social stratification in China: 1955-1996. Demography, 41, 363-384.

Wu, Z., \& Schimmele, C.M. (2005). The healthy migrant effect on depression: Variation over time? Canadian Studies in Population, 32, 271-295.

Xiao, S., \& Wang, X. (Eds.). (1999). Social Support Rating Scale. In Mental Health Scale (Suppl.). Beijing: Chinese Mental Health Publishing House.

Xiao, S.Y., \& Yang, D.S. (1987). The effect of social support on physical and psychological health. Journal of Chinese Psychiatry, 1, 184-187.

Záleská, V., Brabcová, I., \& Vacková, J. (2014). Migration and its impact on mental and physical health: Social support and its main functions. Kontakt, 16, 236241.

Zhang, S., Jiang, C., Wang, P., Liu, M., Liu, H., Yu, C., ... Pan, G. (2008). Epidemiological survey of mood disorders among urban and rural residents in Liaoning Province. Chinese Journal of Prevention and Control of Chronic Diseases, 16, 378381.

Zhao, Z., Huang, Y., Li, J., Deng, H., Huang, X., Su, J., ... Mei, F. (2009). An epidemiological survey of mental disorders in Guangzhou area. Chinese Journal of Nervous and Mental Diseases, 35, 530-534. 